\title{
OS IMPACTOS DA MECANIZAÇÃO DA COLHEITA DE CANA-DE-AÇÚCAR SOBRE OS TRABALHADORES MIGRANTES
}

\author{
Marilda Aparecida de Menezes* \\ Marcelo Saturnino da Silva** \\ Maciel Cover***
}

\section{Introdução:}

Parece consenso para a população brasileira que o setor canavieiro atravessa, nos últimos anos, uma nova fase de expansão, se apresentando, inclusive, como emblema do progresso e do que há de mais moderno, em termos produtivos, no país. Já em 2005, a reportagem publicada na Revista Época dava conta de que,

O álcool tornou-se a maior aposta econômica do país para as próximas décadas. $\mathrm{O}$ crescimento das vendas de carros bicombustíveis no Brasil e a procura por fontes alternativas de energia mais barata e menos poluentes que o petróleo no mundo dispararam o gatilho dos investimentos. Até 2009, 52 novas usinas entrarão em funcionamento com uma injeção na economia que chegará a $\mathrm{R} \$ 12$ bilhões. As 320 usinas já

\footnotetext{
* Professora, PPGCS/UFCG.

** Doutorando, PPGCS/UFCG.

*** Doutorando, PPGCS/UFCG.
} 
$|60|$

Os Impactos da mecanização da colheita de cana-de-açucar sobre os...

existentes também estão sendo ampliadas e modernizadas. O objetivo é aumentar a produção brasileira de 15 bilhões de litros para 27 bilhões nesse período (ÉPOCA, 2005, p. 67)

Gonçalves (2009) utilizando dados da CONAB (2008), afirma que "na safra 2009/2010 o país atingirá a marca de 629 milhões de toneladas de cana", para uma área "estimada em 7,7 milhões de hectares". O autor chama a atenção para o fato de que $55,4 \%$ da cana colhida será destinada à produção de álcool (anidro e hidratado) sendo o restante, $44,6 \%$ destinado a produção de açúcar.

A maior parte desta produção está localizada na região centro-sul, especificamente no Estado de São Paulo, cujas regiões produtoras continuam a registrar aumento, conforme sinalizam dados publicados no portal "Direto da Usina":

A produção de cana-de-açúcar deve ter um aumento de 4,7\% na região de Ribeirão Preto em relação à safra passada, segundo o último levantamento do IEA (Instituto de Economia Agrícola), ligado ao governo do Estado. Araraquara, com crescimento previsto de $10,2 \%$, Barretos $(8,8 \%)$ e Franca $(7,8 \%)$ devem ter, nesta safra, alta acima da média regional no plantio de cana, enquanto áreas mais tradicionais, como Ribeirão (com previsão de crescimento de apenas 1\%) e Orlândia $(1,2 \%)$, mostram uma tendência de menor expansão. No total, a região deve produzir 148 milhões de toneladas de cana, contra 141 milhões de toneladas da safra passada. A área dedicada à cultura estimada pelo IEA para o plantio do produto deve alcançar 1.728 .995 hectares, aumento de 3\% em relação aos 1.672 .906 plantados na safra anterior. As áreas de maior expansão da cultura devem ser Araraquara (12\%) e Franca (11\%). A explicação para esse movimento, segundo especialistas ouvidos pela Folha, é a menor possibilidade de expansão da cana-de-açúcar em áreas 
onde há menos terras disponíveis -e, por consequência, estão mais caras- e seu avanço sobre outras culturas ${ }^{1}$.

$\mathrm{O}$ atual processo de expansão pelo qual vem passando o setor canavieiro é decorrente, dentre outros fatores, do novo ideário ambiental que vem preconizando o fim das fontes de energias tradicionais. Devido ao seu alto grau de poluição, elas colocam em xeque a própria sobrevivência do planeta e, consequentemente, da espécie humana. Assim, urge procurar novas fontes de energias, que sejam limpas e renováveis, o que contribui, dentre outros fatores, para uma maior demanda por etanol, tanto no mercado interno quanto externo, demanda esta fortemente atrelada ao desenvolvimento dos motores "Flex-fuel" 2 . Ainda nas palavras de Gonçalves (2009: p. 02)

\begin{abstract}
Nos últimos anos, a produção de cana-de-açúcar no Brasil tem apresentado um considerável crescimento, que em parte pode ser explicado pelo aumento da demanda nacional e internacional pelo etanol, motivada pelo desenvolvimento da tecnologia 'flexfuel', e em outra parte pela publicidade que se formou em torno do papel dos biocombustíveis, que supostamente representariam a 'solução perfeita' tanto para a crise energética, quanto para os desafios do aquecimento global e das mudanças climáticas, em evidência nesses últimos anos. (grifos dos autores).
\end{abstract}

Todo este crescimento do setor canavieiro não se dá apenas de forma intensiva [maior produtividade numa mesma área], mas, sobretudo, pela incorporação de novas terras às lavouras de

\footnotetext{
${ }^{1}$ Ribeirão Preto: cana avança em áreas menos tradicionais. (Folha de São Paulo, Terça-Feira, 07 de Julho, de 2009) In: “Direto da Usina". Endereço Eletrônico http://www.diretodausina.net/noticia2.aspx? NoticiaId=191.

${ }^{2}$ Tecnologia que permite o uso da gasolina ou do álcool no mesmo motor, permitindo que o consumidor decida pelo tipo de combustível no ato da compra.
} 
$|62|$

Os Impactos da mecanização da colheita de cana-de-açucar sobre os...

cana-de-açúcar das usinas, isto é, de forma extensiva. Esta incorporação se faz mediante a utilização de terras próprias, anteriormente dedicadas a outros empreendimentos produtivos. Outra forma pela qual as empresas do setor canavieiro estão expandindo seus investimentos é mediante a compra ou o aluguel de terras, sendo que esta última opção predomina sobre a primeira. Para o Professor Pedro Ramos ${ }^{3}$, economista da UNICAMP, "O alto custo das terras, provocado pela própria expansão do plantio de cana, faz com que as usinas e os grandes fornecedores prefiram arrendar terras em vez de comprá-las." (Folha de São Paulo, 29/ 04/2007). No caso de arrendamento, a usina paga o equivalente a certa quantidade, determinada no contrato, e medida em toneladas por alqueires.

São vários os impactos causados por esse "boom" da canade-açúcar no território brasileiro, dentre esses aspectos o que mais tem sido pontuado, especificamente por cientistas sociais é o adensamento das migrações sazonais, sobretudo de trabalhadores da região Nordeste que migram para trabalhar no corte de cana nas regiões Sudeste e Centro-Oeste. Aliado à temática da mobilidade dos trabalhadores, outro tema que tem sido analisado pelos pesquisadores são as condições de trabalho nos espaços dos canaviais. Eles têm identificado alto grau de exploração da força de trabalho, através da alta produtividade exigida pelas usinas no corte manual de cana. Na década de 1980, as usinas exigiam que o trabalhador cortasse em média cinco (05) a oito (08) toneladas de cana, por dia; em 1990 esta média sobe para oito (08) a nove (09) toneladas/dia, passando para 10t/dia em 2000 e para doze (12) a quinze (15) toneladas/dia, em 2004.

Outro tema que tem sido objeto das pesquisas é a forma de pagamento adotada pelas empresas canavieiras, isto é, o salário por produção, que tem contribuído para que o trabalhador busque não apenas atingir, mas mesmo ultrapassar continuamente a meta

${ }^{3}$ Entrevista concedida a Folha de São Paulo e divulfgada no portal Açúcar-Ético. Disponível in: http://www.sucre-ethique.org/Cortadores-de-canatem-vida-util.html. 
de produtividade "imposta" pelas usinas. Isso tem sinalizado um desgaste de energia, por parte do trabalhador, análogo ao de um atleta corredor fundista (Alves, 2007), com o agravante de que o trabalhador cortador de cana-de-açúcar não recebe os mesmos cuidados, muito menos tem o mesmo preparo físico de um atleta. Nesse sentido, as condições de trabalho dos cortadores de cana-de-açúcar têm impactado os seus corpos e mentes, marcando-os com o signo do adoecimento, da exclusão social e, não raramente, da morte. (Menezes e Silva, 2010; Novaes, 2007, Silva, 2010).

É importante frisarmos que tais condições de trabalho têm sido continuamente explicitadas e denunciadas por pesquisadores, movimentos pastorais e sociais, bem como pelo Ministério Público e Delegacias do trabalho. A ação desses atores tem dado visibilidade à "sujeira" e ao "sabor amargo" que têm marcado tanto o etanol quanto o açúcar produzido a partir da cana-deaçúcar. Isso contribuiu, inclusive, para a sensibilização da opinião pública internacional e, consequentemente, do mercado consumidor de etanol e de açúcar brasileiro, que, por sua vez, passou a cobrar atitudes dos produtores nacionais no sentido da produção de etanol e açúcar éticos, isto é, sem manchas advindas de condições de trabalho degradante que desrespeitam a dignidade humana ou da degradação do meio ambiente.

\section{O Processo de Mecanização}

Ora, é no bojo desse processo que a busca/construção de uma imagem "ecologicamente correta", por parte de várias empresas produtoras de açúcar e etanol, ganha sentido. Com efeito, trata-se de uma busca por competitividade - num espaço atualmente marcado pela competição interna entre as unidades produtoras -, visando escoar mais facilmente seus produtos no mercado internacional.

Nessa busca, as empresas canavieiras tem se engajado em duas estratégias principais e inter-relacionadas: o fim da queima da cana e do corte manual. Com o fim da queima da cana, 
|64 |

Os Impactos da mecanização da colheita de cana-de-açucar sobre os...

busca-se resolver a degradação ambiental causada pelas atividades do setor, que polui não apenas o ar, mas, também, o discurso do etanol enquanto combustível limpo. Com o fim do corte manual de cana, objetiva-se acabar ou, ao menos, amenizar a degradação do trabalhador e evitar casos extremos como doenças que inutilizam o trabalhador ou chegam a causar-lhe a morte. As duas estratégias deverão ser realizadas via mecanização da colheita da cana-de-açúcar. Vejamos mais detidamente cada uma das estratégias aqui anunciadas.

\begin{abstract}
Atualmente a queima da cana ainda é uma realidade nos canaviais brasileiros, pois, o corte manual é precedido pela queima da planta, haja vista que o rendimento com o corte da cana queimada é, aproximadamente, três vezes maior do que o realizado sem a queima da cana. No entanto, de acordo com Roseiro e Takayanagui (2004 p. 80),
\end{abstract}

Este processo acaba interferindo diretamente na saúde da população, pois a combustão da palha da cana-de-açúcar libera poluentes e o principal dano é o prejuízo à qualidade do ar, e, conseqüentemente, da saúde, pela excessiva emissão de monóxido de carbono e ozônio, trazendo, também, danos ao solo, às plantas naturais e cultivadas, à fauna e à população.

E, continuam os citados autores,

Freqüentemente, as queimadas da cana-de-açúcar matam animais e plantas promovendo o desequilíbrio ecológico, invadem áreas de nascentes circundadas por vegetação ciliar, atingem acidentalmente ou não as áreas de preservação permanente, destruindo florestas inteiras, sujam casas, causam cortes de fornecimento de energia elétrica e impedem a visibilidade em estradas provocando acidentes (Roseiro e Takayanagui, 2004 p. 80).

No Estado de São Paulo, a Lei Estadual n. 11. 241-2007 estabelece o fim da prática da queima de cana-de-açúcar, naquele 
estado, para o ano de 2021 (áreas com declividade menor que $12 \%$ ) e 2031 (áreas com declividade maior que 12\%). No entanto, naquele mesmo ano [2007], foi firmado um protocolo, pela Secretaria do Meio Ambiente do Estado de São Paulo, Secretaria Estadual de Agricultura e Abastecimento e a União da Indústria de Cana-de-açúcar - UNICA, denominado de Protocolo Agroindustrial, o qual prevê a antecipação do fim das queimadas para 2014 (áreas mecanizáveis) e para 2017 em áreas não mecanizáveis.

Como já frisado, o fim da queima de cana-de-açúcar só é economicamente possível diante da possibilidade de mecanização da colheita, pois do contrário, isto é, considerando a permanência do corte manual, não haveria como garantir, sem a queima, os mesmos níveis de produtividade alcançados pelo setor. Assim falar em fim das queimadas no âmbito dos canaviais, implica em anunciar o aumento da mecanização da atividade de colheita da cana-de-açúcar, o que de fato já vem ocorrendo, conforme

\section{Gráfico 01 - Evolução da Mecanização no Estado de São Paulo}

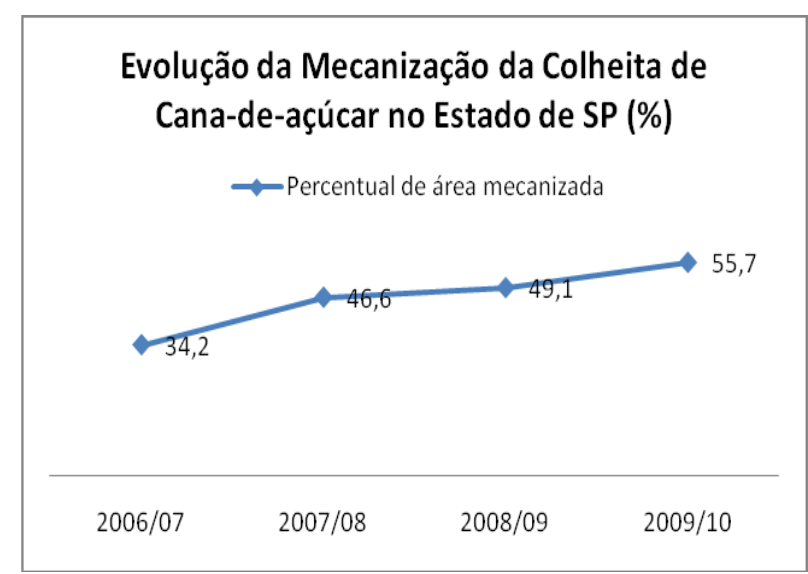

Fonte dos dados: Estimação de Aguair, Rudorff e Silva (2010) 
|66|

Os Impactos da mecanização da colheita de cana-de-açucar sobre os...

podemos perceber, a partir do gráfico 01, que mostra que mais da metade da colheita de cana-de-açúcar no Estado de São Paulo já é realizada de forma mecânica.

A rapidez com que a mecanização avança, pelo menos em território paulista, leva alguns pesquisadores à identificação de um "novo ciclo de modernização" na agricultura canavieira, baseada na expansão acelerada das colheitadeiras de cana. A modernização, no entanto, não é nova, pois a história da agricultura canavieira é acompanhada nos transformações na base tecnológica, nos processos produtivos e nas relações de trabalho.

Como lembra Alves (2007), durante a década de 1960, o Estado brasileiro impôs ao Complexo Agroindustrial Canavieiro - CAI um processo de modernização "visando atender à necessidade de crescimento das exportações" (p. 25). Todavia este mesmo pesquisador nos alerta para o fato de que naquele momento, a mecanização não avançou igualmente em todas as fases da produção e processamento da cana-de-açúcar, tendo sido mais intensa na preparação do solo e em partes do plantio ${ }^{4}$. Assim, tratou-se de um processo de semi-mecanização. Quanto a fase da colheita, esta também passou por uma mecanização apenas parcial, que atingiu, sobretudo, a atividade de carregamento e transporte, deixando, todavia, intacta, a fase do corte ou, nas palavras de Alves, da "colheita propriamente dita, que é retirar a cana do solo e prepará-la para o carregamento" (Alves, 2007: p. 25).

Na década de 1990, o CAI canavieiro viveu o período da desregulamentação, com a saída parcial do Estado, houve um acirramento da concorrência interna e, consequentemente, uma busca por baixar os custos de produção, por parte das unidades produtivas. Ora, nesse momento a estratégia de mecanização volta a ser acionada por parte das empresas do setor, como forma de

\footnotetext{
${ }^{4}$ Segundo Alves (2007: p. 25) o plantio envolve (1) o transporte das mudas até o eito, (2) a abertura dos sulcos ou valas, (3) a colocação das plantas nesses sulcos/valas, (4) o fechamento dos mesmos e (5) a adubação. No momento considerado, 1960, todas as fases do plantio, menos a terceira (colocação da planta, nos sulcos ou valas) foram mecanizadas.
} 
reduzir os custos de produção. Aliado a este fator há que considerar, também, o papel e o peso da greve de Guariba, ocorrida em 1984, quando "os trabalhadores do setor sucroalcooleiro, espontaneamente, levantaram-se contra as precárias condições de vida a que eram submetidos, em um regime que poderia ser considerado de semi-escravidão (Vettorassi, 2007: p. 21). Ao crescimento do nível de organização e do poder de barganha dos trabalhadores, os empresários do CAI canavieiro responderam com a introdução da mecanização, sobretudo na fase do plantio e do corte de cana-de-açúcar, com o objetivo de baixar os custos de produção e pressionar os trabalhadores, visando quebrar-lhes a resistência.

\subsection{Os impactos da mecanização da colheita sobre os trabalhadores:}

Como entender a expansão da mecanização do corte de cana que tem se intensificado na década de 2000. Nossa hipótese é que a mecanização pode ser entendida a partir da orquestração de uma série de fatores, dentre os quais merece destaque a intensificação da tecnologia, o discurso ambiental e aumento nos custos do trabalho manual. Vejamos.

\subsubsection{A intensificação da tecnologia:}

Baccarin e Gebara realçam que até a metade da década de 1990, a mecanização da colheita de cana-de-açúcar não atingiu um patamar significativo. Para os autores, este fato não significa a existência, no período, de uma preocupação, por parte dos empresários do setor canavieiro, com a preservação dos empregos dos cortadores de cana. Ocorre que a adoção da colheita mecânica não apenas demanda uma série de modificações na planta produtiva, como o custo da colheitadeira ainda era relativamente alto. Nas palavras dos autores: 
$|68|$

Os Impactos da mecanização da colheita de cana-de-açucar sobre os...

A adoção da colheitamecânica exige uma série de adaptações, como a maior extensão dos talhões de cana e o uso de cultivares mais adaptadas ao processo. Deve-se também levar em conta que o custo de uma colhedora e do comboio mecânico a ela associado alcança valor relativamente alto, de cerca $R$ \$2,0 milhões (Baccarin e Gebara ${ }^{5}$ ).

No entanto, conforme Arnaldo Antônio Bortoletto, presidente do Sindicato Rural Patronal de Piracicaba, "a tecnologia tem avançado rápido, já temos colheitadeiras com sensores que permitem melhor aproveitamento da cana. Em alguns anos isso [a dificuldade do corte mecanizado em terrenos muito acidentados], já estará resolvido" ${ }^{\prime \prime}, \mathrm{O}$ que também é confirmado por Edison Ustulin ${ }^{7}$, presidente da Comissão Nacional de Cana de Açúcar da FAESP [Federação da Agricultura do Estado de São Paulo], para quem, o avanço da tecnologia deve se refletir na diminuição do preço das máquinas, contribuindo para adensar ainda mais o processo de mecanização. Embora reconheça que a tecnologia tem avançado, Ustulin chama a atenção para a necessidade de avanços nas pesquisas, objetivando tornar ainda maior o aproveitamento da cana colhida pelas máquinas, "aumentar o potencial de colheita em área de declive, além de diminuir o desperdício com restos de cana".

Pelo exposto, podemos concluir que, embora novos modelos de colheitadeiras sejam colocados constantemente no mercado, há sinais de que o preço e a manutenção dessas máquinas sejam, ainda, muito altos, o que tem levado, ao menos, algumas empresas

${ }^{5}$ BACCARIN, José Giacomo e GEBARA, José Jorge. Intensificação do Ritmo e Redução de Postos de Trabalhodos Trabalhadores Canavieiros no Estado de São Paulo, Brasil. Disponível in: www.fcav.unesp.br/baccarin/ Artigo\%2012\%20ALAST.doc. Acesso em 14 de Novembro de 2010.

${ }^{6}$ Entrevista concedida ao jornal eletrônico CAPITALNEWS. Disponível in; http.wurw.capitalnews.com.brver_not.php?id=64631Eed=Agroneg\%C3\%B3cio\&cat=Not\%C3\%ADcias. Acesso em 14 de Novembro de 2010.

${ }^{7}$ Idem, Ibidem. 
a permanecerem com o corte manual, como explica este gerente de recursos humanos de uma usina localizada na região de Catanduva:

A empresa prefere o corte manual, ele mais rentável, ele fica um pouco mais caro, mas você ganha em produção. A safra com máquina fica mais barato, mas o corte manual é mais produtivo. Por quê? A cana acaba o terreno, se você cortar cana com máquina e demorar muito para chover, no próximo ano a produção cai bastante, uma planta de cana, ela é pra seis anos, em média, tem uns que chega a seis, a quatro, tem até sete, hoje... Com a máquina não é possível com a mesma planta você cortar cinco anos (Agemiro, Departamento de Recursos Humanos) \{entrevista realizada por Marcelo Saturnino da Silva em Março de 2010 e transcrita pelo mesmo]

Em conversa com um dos fiscais gerais desta mesma usina, ficamos sabendo que os custos da máquina colheitadeira também ainda é um empecilho para a empresa. Vejamos:

Pesquisador: Tem muita máquina já, Edivalto?

Fiscal: Tem, tem bastante... O projeto é para 2017 se tudo máquina... Só que a usina aqui tem uma visão que enquanto puder cortar queimada, ele vai cortar porque uma máquina é um absurdo... Um milhão de reais uma máquina... A peça mais barata dela é duzentos reais..

Pesquisador: Quebra muito?

Fiscal: Quebra... Oh, ela não precisa quebrar nada, a manutenção dela mensal, se ela não quebrar nada... Nós ta fazendo um curso lá, o cara tava falando... É onze mil por mês, ela dá, só de manutenção, sem quebrar nada... Se você quebrar um pino de centro dela, tem um pino que gira o elevador, ele custa seis mil reais... [Entrevista realizada por Marcelo Saturnino da Silva, em 16 de Julho de 2009 e transcrita pelo mesmo]. 


\subsubsection{O discurso ambiental:}

Outro elemento que vem contribuindo para o atual processo de mecanização do setor canavieiro tem sido o discurso ambientalista, sobretudo quando tal discurso impregna práticas de atores sociais diversos, tais como o mercado consumidor nacional e internacional; os órgãos reguladores e parcelas da sociedade civil organizada, cujo resultado tem sido a pauta do fim das queimadas na agenda do Estado.

A demanda, por parte do mercado consumidor, sobretudo no nível internacional, por um combustível (etanol) realmente limpo torna-se a cada dia mais incompatível com as imagens de cidades poluídas e de populações sofrendo com os efeitos das queimadas de canaviais, além dos riscos aos quais trabalhadores do corte manual são expostos devido à fuligem da cana. Além de que, a colheita manual, nos moldes em que vem sendo realizada, representa a degradação do trabalho humano e fonte de adoecimento e mesmo de morte dos trabalhadores. Dessa forma, conforme expressam Baccarin e Gebara,

Particularmente, há um interesse adicional na substituição da colheita manual, que é precedida da queimada do canavial, pela colheita mecânica de cana sem queimar, que é, justamente, a pretensão de se reforçar, especialmente no mercado internacional, a imagem positiva do etanol como um combustível renovável e menos poluidor do que os derivados do petróleo ${ }^{8}$.

E, nas palavras de Alves,

As exportações de álcool brasileiro, para se expandirem, dependem de o CAI [Complexo Agroindustrial

\footnotetext{
${ }^{8}$ BACCARIN, José Giacomo e GEBARA, José Jorge. Intensificação do Ritmo e Redução de Postos de Trabalhodos Trabalhadores Canavieiros no Estado de São Paulo, Brasil. Disponível in: www.fcav.unesp.br/baccarin/ artigo\%2012\%20ALAST.doc. Acesso em 14 de Novembro de 2010.
} 
Canavieiro] demonstrar para os importadores internacionais que a produção desse 'biocombustível' não agride o meio ambiente nem degrada as condições de trabalho dos trabalhadores, porque a parcela de trabalhadores mais atingida pelas péssimas condições de trabalho deixará de existir: os cortadores de cana (Alves, 2009: p. 155).

\subsubsection{O aumento nos custos do trabalho manual}

Este aumento tem sua origem, por um lado, nas novas exigências legais para a contratação da força de trabalho, por parte das usinas, como consequência da atuação da sociedade civil organizada e do ministério público que dessa forma, tem contribuído para a observância da legislação trabalhista por parte do patronato do setor canavieiro.

Fazem parte desse processo as inúmeras ações que os trabalhadores do setor canavieiro têm levado à justiça do trabalho, visando cobrar os direitos desrespeitados durante o período da safra. Em trabalho recente, Silva e Ribeiro (2010: p. 24) fazem referência "ao grande número de processos trabalhistas movidos contra as empresas, visando ao respeito do cumprimento das normas trabalhistas". Esses mesmos autores chamam atenção para o fato de que as audiências públicas e "as inúmeras fiscalizações feitas pelo Ministério Público nos canaviais, são indicadores do aumento do poder dos trabalhadores", concluindo que "à medida que aumenta a força dos trabalhadores no campo social e a dos agentes do campo jurídico que defendem seus interesses (promotores e juízes), impõem-se novas barreiras à força voraz dos capitais do chamado agro-negócio do açúcar e do álcool".

A título de hipótese sugerimos que a mecanização do corte de cana-de-açúcar deve ser vista/lida também como uma resposta do patronato do setor canavieiro à essas exigências da sociedade civil e dos trabalhadores, como bem enfatizado pelo presidente senhor Fioravanti Mazzo, presidente do sindicato dos trabalhadores rurais do município de Novo Horizonte - SP, 
$|72|$

Os Impactos da mecanização da colheita de cana-de-açucar sobre os...

os trabalhadores vão dando trabalho, as leis vão ficando mais exigentes, as empresas optam pelas máquinas... Os trabalhadores não são mais moderados, eles são bem mais expertos, estão mais escolarizados, ele então cobram mais, atuam mais, tudo isso encarece a empresa, que passa a preferir as máquinas.

Nesse sentido, sugerimos que a orquestração desses fatores tem favorecido a intensificação da mecanização da colheita de canade-açúcar, trazendo para a pauta das discussões os impactos desse processo e, consequentemente, para o destino da importante quantidade de trabalhadores migrantes que têm encontrado no trabalho de cortar cana uma estratégia de reprodução de seu grupo familiar e de concretização de seus projetos pessoais.

O debate sobre o impacto da mecanização da colheita de cana no cotidiano dos trabalhadores rurais assalariados do setor tem recebido ênfases diversas. Assim, alguns observadores e pesquisadores têm realçado que a mecanização, não obstante seu impacto negativo traz também a possibilidade de humanização do trabalho. Teses como esta são ilustradas com exemplos de ex-trabalhadores manuais que "migraram" para a função de operadores de máquinas colheitadeiras e para os quais tal mudança representou mais qualidade de vida. São casos como o de dona Isaura, apresentado por Fernanda Yoneya, no site "Estadão.com.br",

Vaidosa, a ex-cortadora de cana Isaura de Freitas Souza resume bem o que mudou desde que deixou o corte no canavial para se tornar operadora de colhedora de cana-de-açúcar. "Engordei 13 quilos em cinco meses. O trabalho no corte era uma academia; hoje, subo só a escadinha da máquina", compara, rindo. Isaura, que cortou cana por 21 anos, foi uma das primeiras operadoras, vindas do corte, na Usina Costa Pinto, do Grupo Cosan, em Piracicaba (SP). Para chegar à atual função, Isaura fez 440 horas de curso. Teve aulas sobre colheita de qualidade, segurança no trabalho, mecânica 
Ao operar a máquina, o trabalhador estaria mecanicamente "liberto" de todas as mazelas do corte manual. Seu trabalho já não se realizaria a céu aberto e em contato direto com o sol forte, cana queimada e fuligem, o que lhe propiciaria um ambiente de trabalho salubre. Além disso, ao livrar-se do facão, o trabalhador se livraria, igualmente, dos movimentos contínuos e acelerados que o corte manual demanda, evitando, assim, a exaustão e o desgaste físico - transferido para o desgaste do maquinário. Do mesmo modo, haveria também uma diminuição do envelhecimento precoce e as várias formas de doenças (dores de coluna, acidentes de trabalho causado pelo uso do facão etc.).

A pesquisa realizada pela enfermeira Fernanda Ludmilla Rossi Rocha (2007) na região de Ribeirão Preto, revela que permanecendo "a maior parte do tempo dentro das cabines das máquinas, os operadores estão menos susceptíveis aos riscos ocupacionais decorrente da exposição à radiação solar, calor, poeira, fuligem e resíduos agrotóxicos" (Rocha, 2007: p. 110). Neste sentido, tais trabalhadores correm menos riscos de "serem acometidos por doenças respiratórias e cutâneas relacionadas ao corte manual da cana" (Rocha, 2007: p. 110). No entanto, continua a autora,

O conjunto de movimentos realizados no comando
das colhedeiras e o fato de permanecerem sentados
durante toda a jornada de trabalho, não realizarem
pausas regulares e estarem impossibilitados de realizar
atividades de alongamentos ou extensão dos membros
e tronco com freqüência devido às reduzidas medidas
das cabines das colhedeiras, expõem os operadores ao
risco de serem acometidos principalmente por
lombalgias e cervicalgias (Rocha, 2007: 110-111)

${ }^{9}$ YONEYA, Fernanda. Em vez do facão, palm top e computador. Disponível in: http://www.estadao.com.br/noticias/suplementos,em-vez-do-facao-palm-top-ecomputador, $447114,0 . \mathrm{htm}$. 
A autora chama atenção, ainda, para outros riscos aos quais os operadores das colheitadeiras estariam expostos: "acidentes envolvendo animais peçonhentos no momento em que saem da cabine para realizar a manutenção das máquinas ou outras atividades" (p. 111); incêndios provocados pelo superaquecimento do motor das colhedeiras etc. No entanto, a maior incidência de adoecimentos, por parte dos operadores das colhedeiras, está relacionada, ainda segundo Rocha, "as cargas psíquicas decorrentes do trabalho, já que sua atividade exige demasiado esforço mental" (2007: p. 111), sobretudo, devido ao alto grau de atenção e concentração constante que o trabalho exige e que predispõe os operadores à distúrbios psicológicos, além de contribuir para acidentes de trabalho, a exemplo de tombamentos, ocasionados em razão da diminuição da atenção e concentração do trabalhador (Rocha, 2007).

Além disso, os operadores estudados pela pesquisadora em destaque, alternavam os turnos de trabalho, trabalhando metade da safra no turno diurno e a outra metade no turno noturno. Para Rocha, esta alternância de turnos predisporia os trabalhadores "a apresentarem alterações no ritmo cardíaco e fadiga mental, aumentando os riscos de ocorrência de estresses, sofrimento psíquico, envelhecimento precoce, distúrbios no padrão do sono e problemas cardiovasculares e gastrintestinais" (2007: 112).

Outro fator considerado por Rocha é a exposição dos operadores das colhedeiras "a ruídos e vibrações ininterruptas, provenientes do movimento e funcionamento das máquinas", sem a presença de protetores auriculares, o que, segundo ela, potencializaria "os efeitos psicológicos negativos do corte mecanizado" (2007: p. 112).

Também Scopinho chama a atenção para o fato de que as novas tecnologias não têm representado uma diminuição da penosidade, insalubridade e periculosidade do trabalho, mas exatamente o contrário. Em suas palavras: 


\begin{abstract}
a introdução da colhedeira mecânica no corte da cana-de-açúcar não diminui as cargas de trabalho do tipo físico, químico e mecânico existentes no ambiente de trabalho e ainda acentua a presença de elementos que configuram as cargas do tipo fisiológico e psíquico, porque intensificam o ritmo de trabalho. Por exemplo, as jornadas de trabalho dos operadores de máquinas agrícolas variam de 12 até 24 horas, durante a safra. O trabalho no corte mecanizado da cana é organizado em turnos de 8 ou 12 horas e, na época do revezamento, a jornada estende-se até 24 horas de trabalho, com pequenas pausas para descanso e para fazer as refeições no próprio local de trabalho (Scopinho, 2000: p. 97).
\end{abstract}

Embora nossas pesquisas tenham como foco o trabalho manual, por ocasião das visitas de campo aos canaviais paulistas, muitas vezes entramos em contato com operadores de máquinas colheitadeiras cujos relatos atestam o que Rocha vem colocando. Assim é que no ano de 2007, encontramos com Aparecida, na sede do Sindicato dos Trabalhadores Rurais do Município de Novo Horizonte. Não conseguimos saber sua idade, dadas as condições de nosso encontro. Ela estava esperando uma audiência para assinar a rescisão do contrato, com a empresa na qual trabalhava. Tivemos a oportunidade de trocar poucas palavras, pois logo que iniciamos a conversa, a audiência teve início e a trabalhadora precisou adentrar na sala onde a mesma ocorreria. No entanto, embora breve, a conversa foi reveladora. Segundo Aparecida, há três anos que ela trabalhava como operadora de colhedeira numa das usinas do município. Disse-nos que não estava mais suportando e frisou várias vezes que a atividade era muito, muito estressante. Falou-nos da necessidade de atenção que a operação da máquina exige, realçando que qualquer descuido poderia ser causa de acidentes.

Se a utilização da colhedeira não implica em humanização do trabalho para os seus operadores, também não tem contribuído para amenização do trabalho para os trabalhadores que atuam 
$|76|$

Os Impactos da mecanização da colheita de cana-de-açucar sobre os...

no corte manual, conforme explica Novaes, para quem o processo de modernização das usinas de cana-de-açúcar, não gerou benefícios para os trabalhadores, uma vez que,

Tendo essa tecnologia, as usinas passam a exigir desse trabalhador uma alta produtividade em seu trabalho. Os departamentos de relações humanas começam a trabalhar novas formas de gestão, organização do trabalho na perspectiva de aumentar a produtividade desse trabalho. Os resultados são fantásticos nesse sentido. Há dez, ou quinze anos, a média de cana cortada era de seis ou sete toneladas por trabalhador por dia. Hoje se contratam trabalhadores que cortam, no mínimo, dez toneladas de cana por dia. Intensificou-se o ritmo, a jornada de trabalho, então para que o trabalhador seja competitivo com a máquina, a referência dele passou a ser a máquina. Ele tem que cortar tão eficientemente quanto a máquina, e por um salário cada vez menor. Aí temos um processo contraditório, no qual aparece a inovação tecnológica e, ao mesmo tempo, a piora nas condições de trabalho ${ }^{10}$.

Ainda em 2008, convivendo com um grupo de migrantes paraibanos que cortavam cana no interior do Estado de São Paulo, pudemos presenciar a agonia e o desespero dos trabalhadores. Não raramente, ao retornarem do eito, eles chegavam irritados com o fato de terem passado o dia trabalhando na diária, cortando cana crua [na palha], como eles diziam, "para as máquinas". Tratava-se de cortar cana nos locais declinados, onde as máquinas não alcançavam e/ou de abrir caminho, corredores, para a passagem das máquinas. Trabalhando "na diária", os trabalhadores percebiam dezenove reais $(R \$ 19,00)$ por dia, muito

10 Entrevista concedida ao site. "IHU On line".Disponível in: http://www.ihuonline.unisinos.br/uploads/edicoes/1158344143.77pdf.pdf. 
aquém do que poderiam conseguir se trabalhassem por produção, cortando cana queimada. Havia também o fato de que cortando cana crua, na palha, eles estavam se expondo bem mais aos riscos decorrentes de acidentes com animais peçonhentos.

Dessa forma, com a introdução das máquinas e considerando a diversidade dos terrenos de uma mesma empresa, os terrenos mais declinados, são deixados para os trabalhadores manuais, enquanto os mais planos ficam para as máquinas. Mas não são apenas os terrenos, nos relatos dos trabalhadores manuais são constantes as reclamações de que, com as máquinas, além dos piores terrenos, os trabalhadores têm ficado com as piores variedades de cana., como relata Claudionor (Paraibano, cortador de cana): Pra você ver, nós só corta cana caída, e a maquina cana em pé, porque se cortar cana em pé o pião vai produzir muito, tira a cana boa, que fica para a máquina e a cana ruim fica para mão de obra humana. [entrevista realizada em 16 de Julho de 2008, por Marcelo Saturnino e transcrita pelo mesmo] Sentimento este também partilhado por Honda (Paraibano, cortador de cana): "Em São Paulo a cana é mais dura e mais pesada, a cana boa eles deixam para as máquinas. Cana em pé, só quem corta é a máquina". [entrevista realizada em 16 de Julho de 2008, por Marcelo Saturnino e transcrita pelo mesmo]

O trabalhador fica com a cana pior, tendo que trabalhar na cana na palha, o que não rende muito. (Leonildo, paraibano, cortador de cana); [entrevista realizada em 19 de Julho de 2008, por Marcelo Saturnino e transcrita pelo mesmo]

Mas o maior impacto do trabalho morto [as máquinas] sobre o trabalho vivo, está relacionado à possibilidade de extinção ou no mínimo de extrema diminuição do corte manual de cana-de-açúcar. Dessa forma, a colheita manual de cana-de-açúcar viveria atualmente uma morte anunciada pela evolução descrente da demanda de trabalhadores para o corte, por parte das empresas canavieiras, conforme sinaliza o gráfico 02 . 
Gráfico 02 - Evolução da demanda de trabalhadores para a colheita manual de cana-de-açúcar (SP)

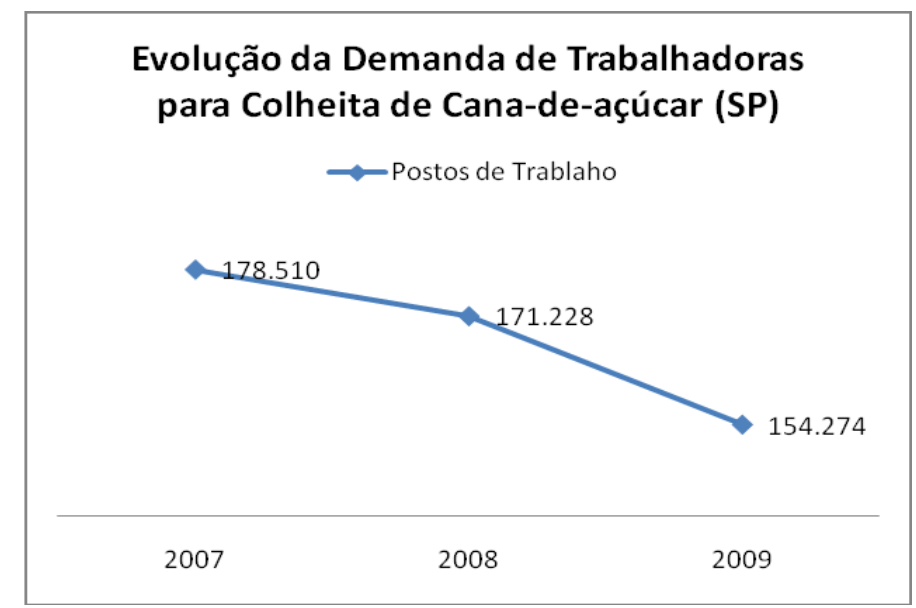

Dados: TEM (Ministério do Trabalho e Emprego)

Como podemos perceber a curva do gráfico 02 é inversamente proporcional a do gráfico 01 , o que é lógico, pois quanto mais elevada a mecanização da colheita de cana-de-açúcar, menos trabalhadores as empresas demandarão para o corte manual. Algumas observações são aqui pertinentes de serem feitas:

Primeiro, é necessário considerar, como foi ressaltado acima que o corte mecanizado não é possível em terrenos de declive, e que isso necessitará de trabalho manual, como nos informa Adilson, encarregado pela frente do corte da cana-de-açúcar de uma Usina localizada no município de Santa Bárbara D'Oeste São Paulo: "os gerentes da usina querem aumentar o corte mecanizado todos os anos, mas os terrenos não ajudam, têm que entender que uns $40 \%$ das terras do grupo é terreno ruim, que máquina não entra, e ali vão precisar de gente do norte para cortar" (Adilson, cearense, encarregado - entrevista realizada por Maciel Cover, em outubro de 2010). 
Dessa forma, mesmo considerando a mecanização atual da colheita de cana-de-açúcar, ainda assim, as empresas terão necessidade do trabalho manual mesmo que sua função seja reduzida à abertura de caminhos para as máquinas, como nos revela o senhor Agemiro, responsável pelo setor de Recursos Humanos de uma usina localizada na região de Catanduva.

Pesquisador: A tendência com a máquina é diminuir
o número de trabalhadores?
Agemiro: Com a máquina vai diminuir um pouco,
mas também tem o problema da expansão da usina
de..., que a usina de... já foi projetada pra ser
aumentada. Só que é o negócio, também se não
tivesse a mecanização, não tinha hoje o pessoal
suficiente para cortar cana, se não tiver mecanização,
o numero de trabalhadores disponível não dão conta
de cortar manual... Eu acho que ainda vai demorar e
ainda vai precisar de muita gente, porque mesmo
onde as máquinas cortam, nós ainda usaremos
turmas para cortar as curvas. Não chega a $100 \%$ de
mecanização e mesmo quando chega, a gente ainda
vai usar o trabalhador.. [entrevista realizada por
Marcelo Saturnino, em Janeiro de 2010 e transcrita
pelo mesmo]

A segunda observação é sobre o processo de expansão atualmente vivido pelas unidades produtivas que tem contribuído para amenizar a tendência de queda na demanda por trabalhadores para o corte manual, isto é, não fosse a expansão das atuais unidades produtivas e o surgimento de novas unidades, concomitantemente a manutenção do atual nível de mecanização, a demanda por trabalhadores para o corte manual estaria sujeita a uma queda ainda mais drástica.

\section{Considerações Finais:}

Não podemos fugir do fato de que a mecanização da colheita de cana, dado o contexto atual, é um processo irreversível, muito 
$|80|$

Os Impactos da mecanização da colheita de cana-de-açucar sobre os...

menos fazermos qualquer tipo de apologia ao corte manual, pois ele representa desgaste intenso e afronta à dignidade da força de trabalho. É mesmo bom que as máquinas "libertem" o trabalho vivo de um trabalho tão degradante. Por outro lado, faz-se necessário colocar a questão sobre os rumos deste contingente de trabalhadores que atualmente tem encontrado na colheita de cana uma estratégia de reprodução de seu grupo familiar e de concretização de seus projetos pessoais de autonomia. Com a mecanização, para onde vai este exército de trabalhadores? Que opções se delineiam em seus horizontes?

Mesmo considerando que, por um lado, a introdução da mecanização acaba com algumas funções, mas cria novos postos de trabalho, por outro, não podemos perder de vista o fato que dificilmente o número dos novos postos de trabalho será suficiente para alocação dos novos desempregados, como bem sinaliza Pedro Ramos, para quem:

Os empregos diretos, mantidos e/ou gerados por essa ocupação qualificada na lavoura, mais os que estão sendo criados pela constituição de novas usinas e destilarias, dificilmente serão suficientes para compensar a menor utilização de trabalho na lavoura canavieira em decorrência daquela mecanização, mesmo em face dos ritmos estimados de crescimentos das produções envolvidas (cana, açúcar e álcool). (Ramos, 2008: p. 323)

Há que considerar também que a alocação dos trabalhadores manuais em novos postos de trabalho demandará novos níveis de escolaridade. Nesse sentido, são pertinentes as palavras de Abreu et. al. (2009: p. 10), para quem:

É difícil se prever como será realocada toda a Mao de obra - se dentro do próprio setor sucroalcooleiro, em outras atividades agropecuárias ou em outros setores econômicos. Presume-se que uma parcela não seja realocada no setor sucroalcooleiro e mesmo em outros setores, em razão do baixo nível de instrução dessa classe trabalhadora, com o conseqüente aumento do desemprego. Especialistas do IEA vêem também essa dificuldade de retorno ao mercado de trabalho dos cortadores 


\begin{abstract}
de cana. Segundo os pesquisadores, antes da reinserção, é necessário que os trabalhadores passem por três fases importantes: motivação do indivíduo para que entenda seu papel no contexto da economia brasileira e a importância de mudar de emprego; requalificação desse trabalhador: muitos devem até mesmo ser alfabetizados; e, por ultimo, o acesso a cursos profissionalizantes para que possam exercer novas funções. (grifos colocados)
\end{abstract}

Durante o ano de 2007, quando residimos com um grupo de migrantes cortadores de cana-de-açúcar no Estado de São Paulo, tomamos conhecimento de vários cursos oferecidos em vários municípios de destino desta força de trabalho, por iniciativa de sindicatos, usinas e do SENAR, no entanto, além da exigência de escolaridade, havia outros empecilhos para a participação dos migrantes: os cursos eram realizados durante o período da safra, alguns mesmo durante o horário de trabalho. Mesmo considerando a possibilidade de um curso noturno, grande parte dos cortadores de cana não se sente motivada a participar de alguma atividade formativa após um dia de trabalho exaustivo no corte de cana. Isso nos faz colocar a hipótese de que tais cursos e, consequentemente, essas oportunidades de trabalho terminam sendo apropriadas, em sua maior parte, pelos trabalhadores nativos.

Numa conversa informal com quatro jovens trabalhadores migrantes, cortadores de cana, no município de Novo Horizonte, o tema das máquinas surgiu espontaneamente:

Pesquisador - Por que você acha que o corte de cana, só vai existir até 2014?

Jovem 4 - Porque depois só dá máquina aí...

Pesquisador - E ai, vocês vão fazer o quê?

Jovem 3 - Ai a gente tem que procurar outros meio né.

Pesquisador - Quais são os outros meio que vocês tem?

Jovem - Procurar outro emprego lá [referência a região de origem] 


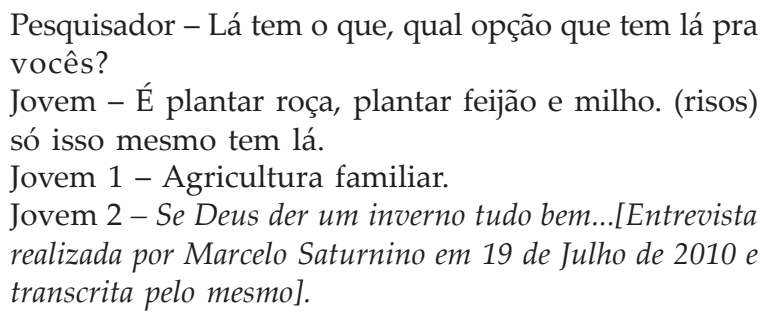

A volta ao lugar de origem, para muitos, revela a falta de opção, de outros horizontes possíveis não vislumbrados. Aí, na origem, as opções continuam as mesmas: a agricultura familiar alternada com outros trabalhos informais: ajudante de pedreiro, descarregador, como a fala deste trabalhador deixa transparecer:

\begin{abstract}
Oxe, viver a gente vive, se fosse assim, gato não vivia, não dá um prego e vive mais bem que o cabra, não paga aluguel, não paga nada, e vive mais bem que o cabra... O cabra muda pra outro serviço, mas pra quem é acostumado a só cortar cana, vai sofrer muito, pra quem ta na usina tá bom, e pra quem não ta... Se eu não cortar cana, vou trabalhar em Domingo [comerciante], descarregando cimento, milho, tá bom demais, eu não nasci cortando cana. Agora ruim é para os fiscais que não sabem faze outra coisa, eu não, eu já fiz de tudo nesta vida.... (Hermínio, 24 anos, migrante paraibano, cortador de cana). [Entrevista realizada por Marcelo Saturnino, em 18 de Julho de 2010 e transcrita pelo mesmo].
\end{abstract}

Pelo exposto, podemos perceber que com a intensificação da mecanização há uma tendência de aumento da informalidade, tanto na região canavieira quanto nos municípios de origem dos migrantes. Alguns trabalhadores, especialmente os jovens com maiores níveis de escolaridade poderão ser alocados tanto no próprio setor, quanto em outros setores da economia, inclusive, no mercado de trabalho urbano na cidade de São Paulo, Sorocaba e outros locais de destino; uma pequena parcela continuará cortando cana-de-açúcar, recebendo menores salários, já que a 
tendência é que o pagamento seja na diária; e se expondo a riscos de acidentes de trabalho, especificamente, os relacionados a picadas de animais peçonhentos.

Os impactos não serão sentidos, apenas, pelos trabalhadores migrantes, mas deverão atingir, também, a dinâmica de seus municípios de origem. Neste sentido é urgente que grupos e organizações, além da sociedade civil e da esfera governamental, dessas localidades comecem a pensar em como se organizarão para receber de volta esta parcela de sua população, o que equivale a pensar as políticas públicas de emprego e renda a nível local.

Uma das possíveis saídas para que os trabalhadores sejam inseridos nas economias das localidades de origem é resolver a questão agrária, que inclusive é um dos vetores que ocasiona os processos de migração sazonal. É necessário que a reforma agrária volte à pauta atual. É de longa data a constatação de que a migração sazonal é uma saída econômica das famílias camponesas do nordeste, devido a alta concentração fundiária e, portanto, não acesso dos agricultores à terra.

Alves (2009) elenca propostas de políticas que compensem a eliminação de postos de trabalho ocasionados pela mecanização no estado de São Paulo. A proposta do autor passa fundamentalmente por uma política de reforma agrária nas áreas de cana onde não será possível adentrar com as máquinas, devido à declividade; associadas a políticas de capacitação e estímulo a produção familiar de alimentos.

Em relação às áreas de origem dos trabalhadores migrantes, cremos que esta proposta seja viável. Políticas de distribuição de terras, associadas ao apoio a agricultura familiar são questões fundamentais para gerar oportunidades de trabalho e renda para as famílias que necessitam destes postos de trabalho, agora eliminados pela mecanização.

Cabe destacar que o mesmo estado brasileiro que investe polpudos recursos no agronegócio canavieiro, estimulando inclusive a mecanização e conseqüentemente a eliminação dos postos de trabalho, tem a responsabilidade de arcar com as conseqüências dessa mecanização para com os trabalhadores migrantes. 
| 84 |

Os Impactos da mecanização da colheita de cana-de-açucar sobre os...

No que tange a políticas publicas para o fortalecimento da agricultura familiar, é necessário que os órgãos públicos repensem a maneira de como distribuir os recursos, visto que boa parte dos recursos do PRONAF (Programa Nacional de Fortalecimento da Agricultura Familiar) são distribuídos nos três estados do Sul. (BIONDI, 2008).

Mas o estado brasileiro não é único responsável por estes trabalhadores que estão sendo afetados pela eliminação de seus postos de trabalho. Como prevê a Constituição Federal, em seu Artigo $7^{\circ}$, Inciso XXVII - é direito dos trabalhadores terem proteção em face da automação, na forma da lei.

Os donos das usinas, beneficiários em alto grau da mecanização das lavouras, também, tem responsabilidade pela eliminação dos postos de trabalho, e, portanto, seria muito proveitoso se parte dos lucros dessas usinas fossem para um fundo que auxilia-se os trabalhadores até arranjaram um novo trabalho.

\section{Referências:}

ABREU, Dirce de; MORAEIS, Luiz Antônio; NASCIMENTO, Ednalva Neves; OLIVEIRA, Rita Aparecida de. Impacto social da mecanização da colheita de cana-de-açúcar. Rev Bras Med Trab. São Paulo • Vols. 4, 5 e $6 \bullet$ Número Especial • Julho de 2009, Disponível in: http://www.sucreethique.org/IMG/pdf/ Impacto_social_da_mecanizacao_da_colheita_de_cana-deacucar.pdf.

AGUIAR, D. A.; RUDORFF, B. F. T.; SILVA, W. F. Monitoramento do modo de colheita da cana-de-açúcar no Estado de São Paulo - ano safra 2009/2010. São José dos Campos: INPE/MCT, 2010. 154p. (Relatório técnico 16685-RPQ/851).

ALVES, Francisco. Políticas Públicas compensatórias para a mecanização do corte de cana crua: indo direto ao ponto. RURIS, Volume 3, n. 1. Campinas/SP, 2009.

Migração de trabalhadores rurais do Maranhão e 
Piauí para o corte de cana em São Paulo. In: Migrantes. Trabalho e trabalhadores no Complexo Agroindustrial canavieiro (os heróis do agronegócio brasileiro). J. R. Novaes e F. Alves (orgs.) São Carlos EdUFSCAR, 2007.

BACCARIN, José Giacomo e GEBARA, José Jorge. Intensificação do Ritmo e Redução de Postos de Trabalhodos Trabalhadores Canavieiros no Estado de São Paulo, Brasil. Disponível in: www.fcav.unesp.br/baccarin/Artigo\%2012\%20ALAST.doc. Acesso em 14 de Novembro de 2010.

BIONDI, Antonio. RS, PR e SC recebem 43\% dos R $\$ 13$ bi para produção familiar. Disponível via internet em http://www.reporterbrasil.org.br/agrocombustiveis/ exibe.php?id=23 Acesso dia 15 de dezembro de 2010.

BRASIL, Constituição Federal do Brasil. Disponível via internet em http://www.planalto.gov.br/ccivil_03/constituicao/ constitui\%C3\%A7ao.htm Acesso dia 14 de dezembro de 2010.

GONÇALVES, Daniel Bertoli. Considerações sobre a expansão recente da lavoura canavieira no Brasil. Rev.. Informações econômicas, SP, v. 39, Out, 2009. Disponível in: ftp://ftp.sp.gov.br/ftpiea/publicacoes/IE/2009/tec7-1009b.pdf.

MENEZES, Marilda Aparecida de \& SILVA, Marcelo Saturnino da. A cana judia de nós! Impactos da migração e da atividade de cortar cana sobre a saúde dos trabalhadores migrantes nordestinos. Texto apresentado no VIII Congresso da ALASRU, Porto de Galinhas, 2010. (mimeo).

NOVAES, J.R.P. Idas e vindas: disparidades e conexões regionais. In: Migrantes. Trabalho e trabalhadores no Complexo Agroindustrial canavieiro (os heróis do agronegócio brasileiro). J. R. Novaes e F. Alves (orgs.) São Carlos EdUFSCAR, 2007.

O paradoxo no mundo do trabalho. IHU On line. Disponível in: http://www.ihuonline.unisinos.br/uploads/ 
edicoes/1158344143.77pdf.pdf.

RAMOS, Pedro. O trabalho na lavoura canavieira paulista: evolução recente, situação atual e perspectivas. In: BUAINAIN, Antônio Márcio e DEDECCA, Cláudio Salvador (Coordenadores) MIRANDA, Carlos e TIBÚRCIO, Breno (Organizadores da Série). Emprego e Trabalho na Agricultura Brasileira. Brasília: IICA, 2008. (Série Desenvolvimento Rural Sustentável; v.9), Disponível in: http://www.iica.int/Esp/regiones/sur/brasil/Lists/ Publicacoes/Attachments/32/Serie\%20DRS\%20vol\%209\%20\%20Emprego\%20e\%20Trabalho\%20na\%20Agricultura\%20Brasileira.pdf.

ROCHA. Fernanda Ludmila. A análise dos fatores de risco do corte manual e mecanizado da cana-de-açúcar no Brasil segundo referencial da Promoção da Saúde. Escola de Enfermagem de Ribeirão Preto, Universidade de São Paulo, 2007. (Tese de Doutorado) (mimeo).

ROSEIRO, Maria Nazareth1 \& TAKAYANAGUI, Ângela Maria Magosso. Meio ambiente e poluição atmosférica: o caso da cana-de-açúcar. In: Rev. Saúde. Vol. 30 (1-2): 76-83, 2004. Disponível in: http://w3.ufsm.br/revistasaude/2004/30\%2812\%2976-83,\%202004.pdf.

SCOPINHO, Rosemeire Aparecida. Qualidade total, saúde e trabalho: uma análise em empresas sucroalcooleiras paulistas. In: RAC, v. 4, n. 1, Jan./Abr. 2000: 93-112. Disponível in: http://www.scielo.br/pdf/rac/v4n1/v4n1a06.pdf.

SILVA, Maria Aparecida de Moraes \& RIBEIRO, Jadir Damião. Violação dos direitos e formas de resistência nos canaviais paulistas. Texto apresentado no VIII Congreso da ALASRU, Porto de Galinhas, 2010. (mimeo).

SILVA, Maria Aparecida de Moraes. Trabalho e trabalhadores na região do "mar de cana e do rio de álcool.: In: J. R. Novaes e F. Alves (orgs.) Migrantes: trabalho e trabalhadores 
no complexo agroindustrial canavieiro (os heróis do agronegócio brasileiro).São Carlos, EduFSCAR, 2007.

SORIMA NETO, João e NEVES, Maria Laura. A Revolução da cana. Revista Época, Rio de Janeiro, no 388, 24 de outubro de 2005.

VETTORASSI, Andréa. Partindo para a cidade garantida e proibida. In: J. R. Novaes e F. Alves (orgs.) Migrantes: trabalho e trabalhadores no complexo agroindustrial canavieiro (os heróis do agronegócio brasileiro). São Carlos, EduFSCAR, 2007. 